\title{
Prospecção Tecnológica e Patentes de Leveduras Nutricionais
}

\author{
Technological Prospecting and Patents of Nutricional Yeast
}

\author{
Natasha Cecchi Evangelista ${ }^{1}$ \\ Grace Ferreira Ghesti ${ }^{1}$ \\ Nádia Skorupa Parachin ${ }^{1}$ \\ ${ }^{1}$ Universidade de Brasília, Brasília, DF, Brasil
}

\begin{abstract}
Resumo
As leveduras nutricionais vêm despontando como alternativa aos suplementos alimentares tradicionais, pois possuem alta concentração de proteínas, aminoácidos, vitaminas do complexo B e podem ser consumidas por indivíduos com dietas restritivas, como vegetarianos e intolerantes a lactose. O presente trabalho teve como objetivo a prospecção tecnológica, análise e compreensão do escopo e das características das patentes relacionadas à levedura nutricional, por meio dos bancos de dados do Instituto Nacional da Propriedade Industrial (INPI), European Patents Office (Espacenet) e United States Patent and Trademark Office (USPTO), do emprego do software Microsoft Excel, e utilizando a metodologia proposta por Mayerhoff (2008), que divide a prospecção em quatro fases distintas preparatória; pré-prospectiva; prospectiva e pós-prospectiva. O processo de busca envolveu uma etapa de refinamento manual das 227 patentes encontradas, para que aquelas sem enquadramento como leveduras nutricionais fossem excluídas. Os resultados refinados finais obtidos de apenas 64 depósitos e 2 concessões de patentes relacionados com leveduras nutricionais - pesquisados nos bancos de dados no período de 1925 a junho de 2018 - evidenciam que o mercado mundial ainda investe pouco nesse tipo de produto. Portanto, essa área ainda não se encontra saturada, com possibilidade de ser mais explorada e receber investimentos.
\end{abstract}

Palavras-chave: Levedura nutricional. Prospecção tecnológica. Patentes.

\begin{abstract}
Nutritional yeast has been emerging as an alternative to traditional dietary supplements, because it has a high concentration of proteins, amino acids, and B-complex vitamins and can be consumed by those with restrictive diets, such as vegetarians and lactose intolerant. The present work aimed at the technological prospection, analysis and understanding of the scope and characteristics of patents related to nutritional yeast, through INPI, Espacenet and USPTO databases, using the Microsoft Excel software, and the methodology proposed by Mayerhoff (2008), which divides prospecting into four distinct phases - preparatory; pre-prospective; prospective and post-prospective. The search process involved the manual refinement of the 227 patents found, so that those that did not fit as nutritional yeasts were excluded. The results obtained of only 64 deposits and 2 patent concessions related to nutritional yeasts - which were searched in the databases between 1925 and June of 2018 - show that the world market still invests little in this type of product. Therefore this area is not yet saturated, with the possibility of being exploited and receiving investments.
\end{abstract}

Keywords: Nutritional yeast. Technological prospecting. Patents.

Área tecnológica: Propriedade intelectual. 


\section{Introdução}

Baumol (2003), em seu livro "The Free Market Innovation Machine", afirma que a inovação é obrigatória para o crescimento e sobrevivência de uma empresa no sistema capitalista, sem ela a empresa está fadada ao fracasso. Portanto, a busca pela inovação deve ser um ponto focal para qualquer empresário, já que o valor de mercado de sua firma está ligado, mesmo que de forma intangível, aos investimentos em pesquisa e desenvolvimento (P\&D) (GRILICHES; MARKET, 1984). Nessa busca, há duas ferramentas de suma importância possíveis de serem utilizadas: a prospecção tecnológica e o registro de patentes.

De acordo com Santos et al. (2010) prospecção "[...] significa identificar quais são as oportunidades e necessidades mais importantes para a pesquisa e desenvolvimento no futuro". Portanto, esse método permite o entendimento do estado da arte, a análise da concorrência no mercado e a tentativa de previsão do possível estado futuro da tecnologia estudada para, a partir dos resultados, basear um planejamento estratégico e a tomada de decisão de investimentos em P\&D. Esse tipo de iniciativa posiciona a empresa como uma instituição ativa, em que não fica à mercê das mudanças tecnológicas, busca a inovação e se prepara para as transformações do mercado (MAYERHOFF, 2008).

Mayerhoff (2008), afirma que o processo de prospecção tecnológica pode ser dividido em quatro fases: 1) preparatória, em que se define os objetivos, escopo, abordagem e metodologia; 2) pré-prospectiva, na qual é realizado o detalhamento da metodologia e o levantamento da fonte de dados; 3 ) prospectiva, em que ocorre a coleta, o tratamento e análise de dados; 4) pós-prospectiva, com foco na comunicação dos resultados, na implementação das ações e no monitoramento.

Os documentos de maior confiabilidade e prontidão disponíveis para realização da prospecção tecnológica são as patentes. Encontradas nos sistemas de propriedade intelectual, como do Instituto Nacional da Propriedade Industrial (INPI), Espacenet - pertencente ao European Patents Office - e do United States Patent and Trademark Office (USPTO), esses dados estão disponíveis online e têm acesso gratuito, tornando-se uma das melhores fontes para o pesquisador.

Patente, de acordo com o INPI (2012),

[...] é um título de propriedade temporário, oficial, concedido pelo Estado, por força de lei, ao seu titular ou seus sucessores, que passam a possuir direitos exclusivos sobre o bem, seja de um produto, de um processo de fabricação ou aperfeiçoamento de produtos e processos já existentes, objetos de sua patente.

Vale ressaltar que existem dois tipos distintos de patentes, patente de invenção e patente de modelo de utilidade. A primeira visa à proteção das criações de caráter técnico, para solucionar problemas em uma área tecnológica específica, caracterizando-se por ser uma solução nova para um problema existente e tem vigência de 20 anos; a segunda protege objetos que, apresentando nova forma ou disposição e sem visar um efeito técnico peculiar, destinam-se a melhorar o uso do objeto e tem vigência de 15 anos (INPI, 2012).

Tendo isso em vista, o artigo realizará uma prospecção tecnológica e análise de patentes relacionadas à levedura nutricional, sendo ela utilizada como uma nova e importante fonte de proteína para consumo humano e que vem despontando atualmente como suplemento 
nutricional e substituto de fontes convencionais de proteína, como proteínas de fonte animal e ainda suplementos a base de proteínas do leite (whey). Para tal, este artigo abordará primeiro o contexto em que se insere a levedura nutricional, para então passar à metodologia utilizada na busca e análise de patentes, seguido da análise dos resultados encontrados e conclusão.

\subsection{Contextualizando a Levedura Nutricional}

Leveduras são fungos que se apresentam como seres unicelulares, tipicamente esféricos ou ovalados e anaeróbios facultativos. Essa última característica permite sua utilização na produção de alimentos e bebidas, como pães, vinhos e cervejas. As espécies de Saccharomyces são as mais comumente utilizadas pelo homem, destacando-se a $S$. cerevisiae.

Uma nova utilidade para essas leveduras vem despontando como suplemento alimentar. As chamadas leveduras nutricionais são constituídas principalmente de $S$. cerevisiae produzidas de acordo com as boas práticas de fabricação da Agência de Vigilância Sanitária (ANVISA) - o que as tornam propícias para consumo humano - que passam por processo de secagem, para que se conserve na prateleira e a proteína fique mais acessível para o consumo humano. São vendidas principalmente em pó ou em flocos, mas também são encontradas em tabletes, cápsulas ou líquido (JACH; SEREFKO, 2018). Essa biomassa de levedura seria classificada, de acordo com a ANVISA na Resolução $n^{\circ}$ 18, de 30 de abril de 1999, como alimento funcional ou nutracêutico. Essa resolução define propriedade funcional de um alimento como "[...] aquela relativa ao papel metabólico ou fisiológico que o nutriente ou não nutriente tem no crescimento, desenvolvimento, manutenção e outras funções normais do organismo humano." (ANVISA, 1999).

Vale ressaltar que há diferença entre levedo e levedura nutricional, a primeira é obtida como subproduto da fermentação cervejeira, enquanto a segunda é cultivada exclusivamente para suplementação, não se caracterizando como subproduto de nenhum processo e, portanto, sem compostos secundários indesejáveis (BEKATOROU; PSARIANOS; KOUTINAS, 2006). Por suas características mais adequadas para o estudo deste artigo, o foco será apenas na levedura nutricional.

A biomassa de levedura utilizada como suplemento alimentar apresenta muitas vantagens em relação aos suplementos mais tradicionais, como aqueles que utilizam proteína do whey em sua composição. Ela contém alto teor de proteínas e aminoácidos essenciais; é fonte de vitaminas do complexo B; pode ser enriquecida com microelementos essências, como zinco e ferro; possui taxa de crescimento mais elevada que animais e plantas, produzindo elevadas quantidades de proteína com maior produtividade além de serem ecologicamente corretas; pode ser consumida por pessoas com dietas restritivas, como vegetarianos, veganos e intolerantes à lactose.

Além disso, leveduras são fáceis de se propagarem e coletar, pois possuem capacidade de floculação e têm tamanho celular elevado. Portanto, as leveduras nutricionais surgem como uma ótima alternativa na indústria de alimentos saudáveis e suplementos alimentares (JACH; SEREFKO, 2018). Algumas das empresas que fornecem leveduras nutricionais encontradas no Brasil atualmente são a NOW Foods, Bob’s Red Mill e Vegan Way (Quadro 1). 
Quadro 1 - Empresas fornecedoras de leveduras nutricionais com produtos presentes no Brasil em 2018

\begin{tabular}{|c|c|}
\hline EMPRESA & TIPOS DE PRODUTOS COM LEVEDURAS NUTRICIONAIS \\
\hline NOW Foods & Levedura nutricional em flocos; Levedura nutricional em Pó \\
\hline Bob's Red Mill & Levedura nutricional em flocos \\
\hline Vegan Way & $\begin{array}{c}\text { Levedura nutricional sabor natural; Levedura } \\
\text { nutricional sabor fumaça e alecrim }\end{array}$ \\
\hline
\end{tabular}

Fonte: Elaborado pelos autores deste artigo (2018)

Notando-se as qualidades da biomassa de leveduras, a oportunidade de mercado, o déficit de informações e dados sobre o assunto, e utilizando a prospecção tecnológica de patentes, o artigo almeja analisar e compreender o escopo das patentes relacionadas à levedura nutricional, assim como a quantidade de patentes depositadas e concedidas, o ano de depósito e concessão e quais países e empresas depositaram.

\section{Metodologia}

Utilizando-se do método proposto por Mayerhoff (2008) - que visa uma busca e análise mais eficiente dividindo a prospecção em quatro fases distintas: preparatória; pré-prospectiva; prospectiva; pós-prospectiva - na fase 1 (preparatória) foram definidos os objetivos da prospecção, que já foram elucidados anteriormente, o escopo, a abordagem e a metodologia. O estudo empregou em sua metodologia bases de dados gratuitas e acessíveis a todos: INPI, Espacenet e USPTO. A busca, que englobou patentes no período de 1925 a junho de 2018, e análise de patentes foram feitas de modo manual, empregando o programa Microsoft Office Excel 2016 para tratamento e análise dos dados obtidos. Decidiu-se que o processo de busca seria realizado com alto refinamento - no qual, nas buscas com resultados mais relevantes, as patentes seriam selecionadas qualitativamente de acordo com seu enquadramento como levedura nutricional (Quadro 2). Esse método foi aplicado devido à alta especificidade do tipo de patente procurado - leveduras nutricionais para consumo humano como suplemento alimentar - e que o processo seria realizado manualmente. Objetivou-se a análise da quantidade de patentes depositadas e concedidas, do ano de depósito e concessão, dos países que as depositaram e a análise das empresas ou instituições que mais depositaram patentes do assunto, além do objetivo da patente.

Quadro 2 - Critérios de exclusão ou inclusão das patentes analisadas qualitativamente

\begin{tabular}{|c|c|}
\hline CRITÉRIOS DE ExCLUSÃo & CRITÉRIOS DE INCLUSÃo \\
\hline Uso para consumo animal & Uso para consumo humano \\
\hline Não conter levedura no produto final & Conter levedura no produto final \\
\hline Conter apenas compostos específicos da levedura & Conter a levedura inteira \\
\hline Uso em outras finalidades que não alimentares & Uso para suplementação alimentar ou como alimento \\
\hline
\end{tabular}

Fonte: Elaborada pelos autores deste artigo (2018) 
Na segunda fase (pré-prospectiva), foram definidas as palavras-chave para a busca, os truncamentos, os operadores lógicos e os códigos da classificação internacional de patentes (IPC) a serem utilizados (Quadro1). As palavras fixas selecionadas foram a) yeast/levedura dependendo do idioma do banco de dados, combinadas com as variáveis b) nutri*, c) supplement*/suplement*, d) diet*, e) protein* ou f) nutraceutic*, sempre utilizando "levedura/yeast" e apenas uma das opções (b, c, d, e ou f) conectadas com o operador "AND". Os códigos da IPC selecionados pela análise dos códigos de patentes relacionadas ao assunto foram A23J 3/20 e A23L 33/14 (Figura 1). Na fase prospectiva propriamente dita, a primeira busca feita no Espacenet com "yeast and nutri*" resultou em mais de 10.000 resultados, a busca foi refinada para "yeast and nutri*" com o código A23J3/20 gerando 10 resultados, desses resultados, por meio de uma análise qualitativa (Quadro 3), apenas 5 eram relevantes. Esse processo de busca geral para refinamento foi realizado com todas as combinações entre o termo fixo (levedura/ yeast), os termos variáveis (b, c, d, e, f) e ambos os códigos IPC.

Quadro 3 - Estratégia de busca

\begin{tabular}{|c|c|c|c|}
\hline ESPACENET & USPTO & INPI & CóDIGOS IPC \\
\hline yeast and nutri* & yeast and nutri\$ & levedura and nutri* & A23J 3/20 \\
\hline yeast and supplement* & yeast and supplement\$ & levedura and suplement* & levedura and diet* \\
\hline yeast and diet* & yeast and diet\$ & levedura and protein* & A23L 33/14 \\
\hline yeast and protein* & yeast and protein\$ & levedura and nutracêutic* & \\
\hline yeast and nutraceutic* & yeast and nutraceutic\$ & lever & \\
\hline
\end{tabular}

Fonte: Elaborada pelos autores deste artigo (2018)

Figura 1 - Definições dos códigos IPC

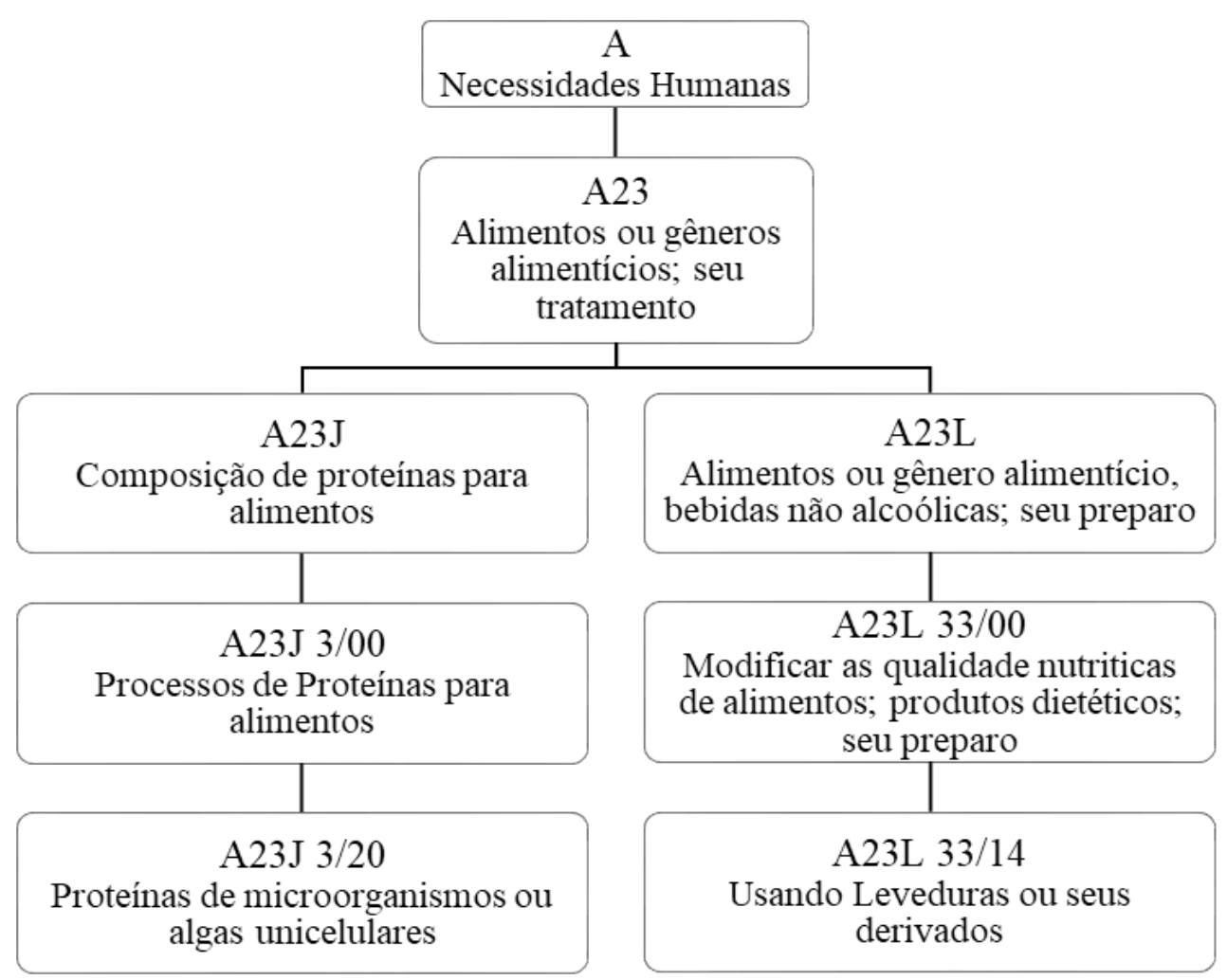

Fonte: Elaborada pelos autores deste artigo (2018) 
Na fase prospectiva (terceira fase), os resultados das buscas no INPI e USPTO foram plotados manualmente no Excel, enquanto que os resultados do Espacenet foram exportados já no formato de planilhas (xlsx), pela funcionalidade que o próprio site oferece. Nas buscas mais refinadas, a análise qualitativa das patentes foi realizada com base nos critérios d Quadro1. Assim a partir dessa análise retiraram-se as patentes que não se enquadravam nos critérios pré-estabelecidos, como aquelas que usavam leveduras para outras finalidades - que não no auxílio para a nutrição ou suplementação da dieta humana - $e$ as que no seu produto final não continham leveduras (Quadro 1). Os dados selecionados foram tratados manualmente no Excel, sendo excluídos os duplicados, para a montagem de gráficos e tabelas e análise de resultados.

As análises foram realizadas em relação ao número de patentes, ano de depósito e concessão das patentes, o país de depósito, as empresas a que pertenciam e o que protegiam. Também foram realizadas análises gerais, comparativas e individuais de cada banco de dados.

Na quarta fase (pós-prospectiva) o foco deste artigo será apenas na comunicação dos resultados, a qual ocorrerá na seção a seguir.

\section{Resultados e Discussão}

Em uma primeira busca utilizando o termo "levedura/yeast", foram encontrados mais de dez mil resultados no Espacenet, mais de trinta mil no USPTO e 515 no INPI. Para que a pesquisa fosse mais bem direcionada, foram utilizadas outras palavras-chave e códigos IPC, dessa forma foram produzidos resultados mais refinados e com maior qualidade. Como a pesquisa com palavras-chave e códigos IPC não obteve resultados no USPTO, optou-se por refazer a busca utilizando apenas os códigos IPC (Tabela 1 e Figura 2).

Em uma análise qualitativa das patentes, foi constatado que muitas delas não estavam diretamente relacionadas ao tema de leveduras nutricionais, portanto os documentos foram selecionados manualmente para que apenas os adequados fossem mantidos $e$ analisados $e$ os resultados fossem produzidos com maior significância (Tabela 1 e Figura 2). O resultado do refinamento gerou um total de 64 patentes, sem duplicidade, que foram então analisadas em detalhe.

Tabela 1 - Resultados de busca de patentes em banco de dados que utilizam leveduras como fonte nutricional

\begin{tabular}{cccc}
\hline Palavras-chave & EsPacenet & USPTO & INPI \\
Tétulo E Resumo & Título E Resumo & Resumo \\
\hline yeast/ levedura & $>10.000$ & 30096 & 515 \\
\hline yeast and nutri*/ levedura and nutri* & $>10.000$ & 171 & 34 \\
\hline yeast and supplement*/ levedura and suplement* & 1748 & 17468 & 19 \\
\hline yeast and diet*/ levedura and diet* & 1546 & 17435 & 11 \\
\hline yeast and protein*/ levedura and protein* & 10000 & 18102 & 99 \\
\hline yeast and nutraceutic*/ levedura and nutracêutic* & 17 & 8 & 4 \\
\hline Subtotal Palavras-chave & $>30000$ & 83280 & 682
\end{tabular}




\begin{tabular}{|c|c|c|c|c|}
\hline & Palavras-chave + Códigos IPC & $\begin{array}{c}\text { Espacenet } \\
\text { Título E Resumo }\end{array}$ & $\begin{array}{c}\text { USPTO } \\
\text { Título E Resumo }\end{array}$ & $\begin{array}{l}\text { INPI } \\
\text { Resumo }\end{array}$ \\
\hline \multirow{6}{*}{$\begin{array}{l}\text { A23J } \\
3 / 20\end{array}$} & yeast and nutri*/ levedura and nutri* & 10 & 0 & 0 \\
\hline & $\begin{array}{l}\text { yeast and supplement*/ } \\
\text { levedura and suplement* }\end{array}$ & 5 & 0 & 0 \\
\hline & yeast and diet*/ levedura and diet* & 3 & 0 & 0 \\
\hline & yeast and protein*/ levedura and protein* & 42 & 0 & 1 \\
\hline & $\begin{array}{c}\text { yeast and nutraceutic*/ levedura } \\
\text { and nutracêutic* }\end{array}$ & 0 & 0 & 0 \\
\hline & Apenas o código IPC & $\mathrm{x}$ & 11 & $\mathrm{x}$ \\
\hline \multirow{7}{*}{$\begin{array}{l}\text { A23L } \\
33 / 14\end{array}$} & yeast and nutri*/ levedura and nutri* & 7 & 2 & 1 \\
\hline & $\begin{array}{l}\text { yeast and supplement*/ } \\
\text { levedura and suplement* }\end{array}$ & 33 & 2 & 2 \\
\hline & yeast and diet*/ levedura and diet* & 38 & 0 & 1 \\
\hline & yeast and protein*/ levedura and protein* & 57 & 0 & 1 \\
\hline & $\begin{array}{c}\text { yeast and nutraceutic*/ levedura } \\
\text { and nutracêutic* }\end{array}$ & 0 & 0 & 1 \\
\hline & Apenas o código IPC & $\mathrm{x}$ & 11 & $\mathrm{x}$ \\
\hline \multirow{2}{*}{\multicolumn{2}{|c|}{ Subtotal Palavras-chave + Códigos IPC }} & 195 & 26 & 6 \\
\hline & & $\begin{array}{c}\text { Espacenet } \\
\text { Título e Resumo }\end{array}$ & $\begin{array}{c}\text { USPTO } \\
\text { Título E Resumo }\end{array}$ & $\begin{array}{c}\text { INPI } \\
\text { RESUMO }\end{array}$ \\
\hline & Resultados relevantes (sem duplicidade) & 55 & 6 & 5 \\
\hline & Total de patentes (sem duplicidade) & \multicolumn{3}{|c|}{64} \\
\hline
\end{tabular}

Fonte: Elaborada pelos autores deste artigo (2018)

Figura 2 - Número de patentes das buscas refinadas pelo IPC e número de resultados relevantes depois das análises qualitativas

Número de Patentes Resultantes de Buscas Refinadas

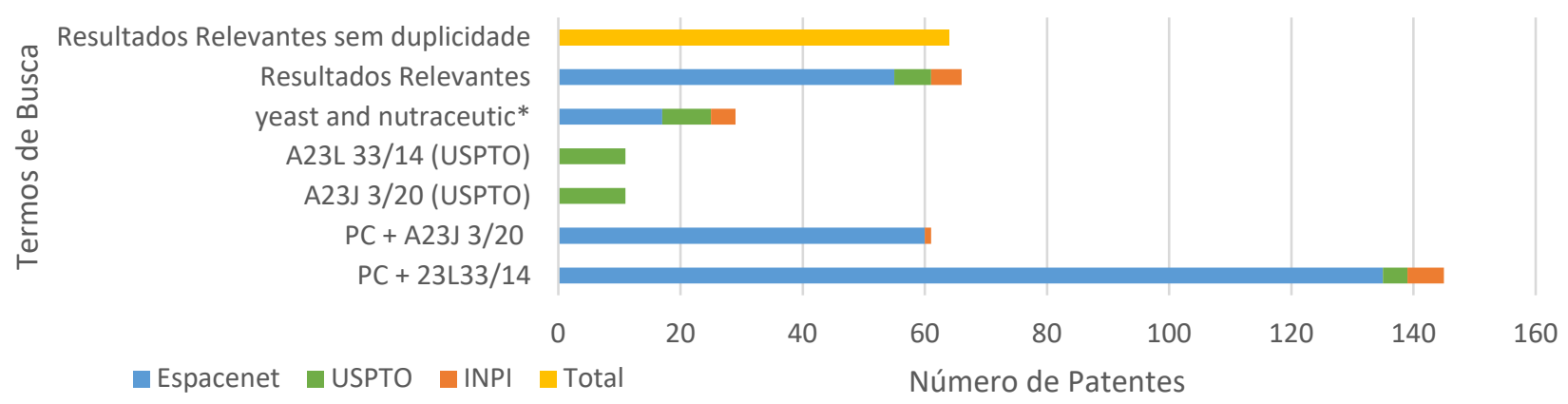

Nota: PC: palavras-chave.

Fonte: Elaborada pelos autores deste artigo (2018) 


\subsection{Evolução Histórica}

Em 1925, a primeira patente relacionada a leveduras nutricionais, denominada "Process for the production of a nutrient preparation rich in vitamins", foi depositada por Hugo Liebers no Reino Unido. Ela abordava um processo para uma preparação nutritiva rica em vitaminas, que levava leveduras em sua composição. A partir desse período, poucas patentes foram depositadas até 1973, ano em foram realizados cinco depósitos nessa área, sendo quatro deles pertencentes à British Petroleum Company. Nos anos seguintes, houve uma queda e estabilização no número de depósitos, até que de 2010 a 2017 ocorreu um aumento significativo no número de depósitos, saindo de um ou dois depósitos por ano nos anos anteriores para seis depósitos em 2010, chegando em sete depósitos em 2016 e oito depósitos e uma concessão em 2017, demonstrando o crescimento do interesse do mercado mundial pelo tema. Apenas duas patentes foram constatadas como concedidas desde 1925, porém esse número foi influenciado pela falta de dados nos bancos pesquisados e, principalmente, pelo não pagamento das taxas por seus depositantes, dando fim ao processo de análise do documento (Figura 3).

Figura 3 - Número total de depósitos e concessões de patentes por ano

Número de Patentes Totais - Evolução Histórica

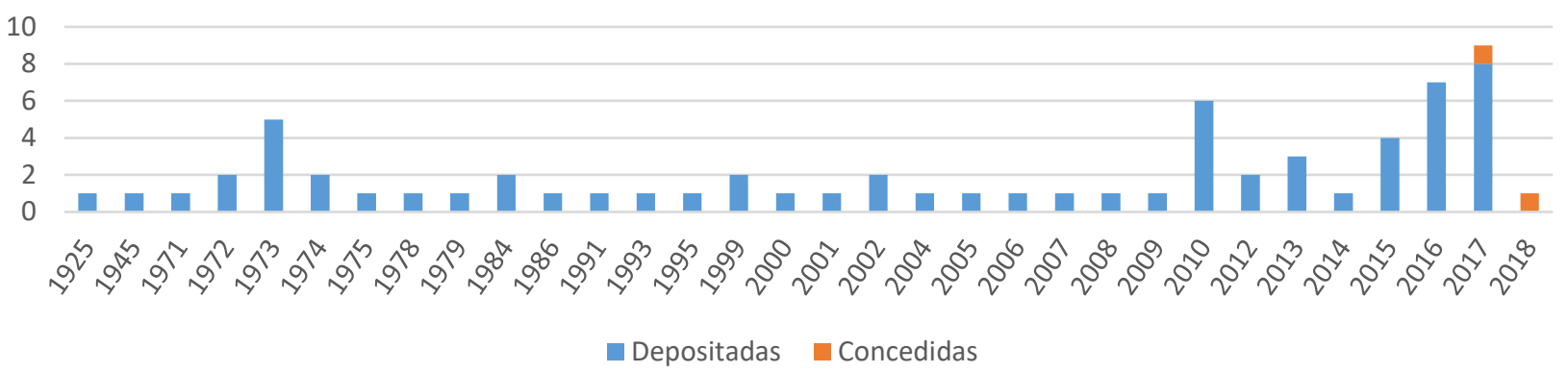

Fonte: Elaborada pelos autores deste artigo (2018)

\subsection{Análise por País}

Por meio de uma análise individual de cada banco de dados, constata-se que o Brasil pouco investiu em leveduras nutricionais, pois o número de depósitos foi baixo quando comparado a outros países como China e Reino Unido. Além disso, é importante enfatizar que até o presente momento nenhuma patente nessa área foi concedida no País, porém duas dessas patentes ainda estão sob análise (Quadro 4 e Figura 4A). O baixo número de depósitos se repete nos Estados Unidos, porém observa-se uma elevação desses números nos últimos anos, demonstrando uma possível mudança de tendência de mercado no País (Figura 4B). 
Quadro 4 - Patentes em análise no Brasil

\begin{tabular}{|c|c|c|c|c|c|c|}
\hline Título & $\begin{array}{l}\text { NÚMERO DE } \\
\text { PUBLICAÇÃo }\end{array}$ & País & $\begin{array}{c}\text { DATA DE } \\
\text { APLICAÇÃo }\end{array}$ & $\begin{array}{c}\text { DATA DE } \\
\text { AUBLICAÇÃo }\end{array}$ & Aplicante (s) & $S_{\text {tatus }}$ \\
\hline $\begin{array}{l}\text { Complexos minerais contendo } \\
\text { parede celular, processos de } \\
\text { preparação, composições } \\
\text { que os contém e uso desses } \\
\text { complexos minerais }\end{array}$ & PI 1002480-8 & $\mathrm{BR}$ & 2010 & 2012 & $\begin{array}{l}\text { NPA - Núcleo } \\
\text { De Pesquisas } \\
\text { Aplicadas } \\
\text { Ltda. (Br/Sp) }\end{array}$ & $\begin{array}{c}\text { Em } \\
\text { análise }\end{array}$ \\
\hline $\begin{array}{l}\text { Produção } \\
\text { da levedura Saccharomyces } \\
\text { cerevisiae ativa enriquecida } \\
\text { com íons ferroso e férrico } \\
\text { incorporados mediante } \\
\text { adição aos meios de cultivo }\end{array}$ & $\begin{array}{c}\text { BR } 102012 \\
0241692\end{array}$ & $\mathrm{BR}$ & 2012 & 2014 & $\begin{array}{l}\text { Universidade } \\
\text { Federal } \\
\text { do Paraná } \\
\text { (BR/PR) }\end{array}$ & $\begin{array}{c}\text { Em } \\
\text { análise }\end{array}$ \\
\hline
\end{tabular}

Fonte: Elaborado pelos autores deste artigo (2018)

Figura 4 - Patentes depositadas por ano

A

Patentes Depositadas por Ano - INPI

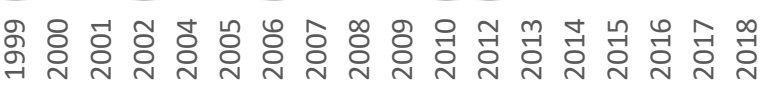

- Depositadas Concedidas

$\mathrm{B}$

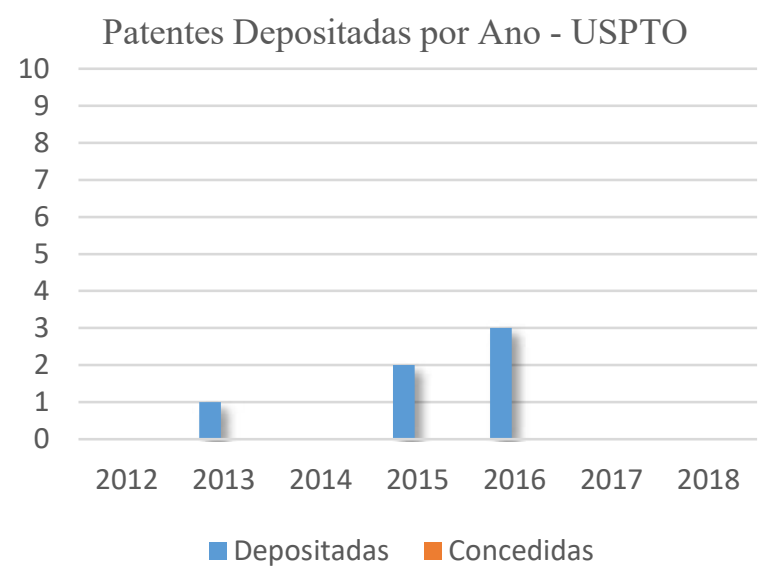

Patentes Depositadas por Ano - USPTO

Nota: A Figura "A" apresenta o número de depósitos e concessões de patentes pelo banco de dados do INPI, sendo o total de concessões igual a zero. A Figura "B" apresenta o número de depósitos e concessões de patentes pelo USPTO, sendo o total de concessões também igual a zero.

Fonte: Elaborada pelos autores deste artigo (2018)

Ao partir para a observação dos depósitos pelo mundo, o Brasil ganha destaque, aparecendo em quarto lugar, empatado com a República Checa. A China lidera com 20 depósitos e uma patente concedida, seguida do Reino Unido com dez depósitos e EUA com oito (Figura 5). O único país, além da China, com patente concedida é o Japão, que aparece com quatro depósitos e uma concessão. Ambas as concessões ocorreram recentemente, em 2017 e 2018 (Quadro 5). 
Figura 5 - Patentes depositadas e concedidas por país

Patentes Depositadas e Concedidas por País

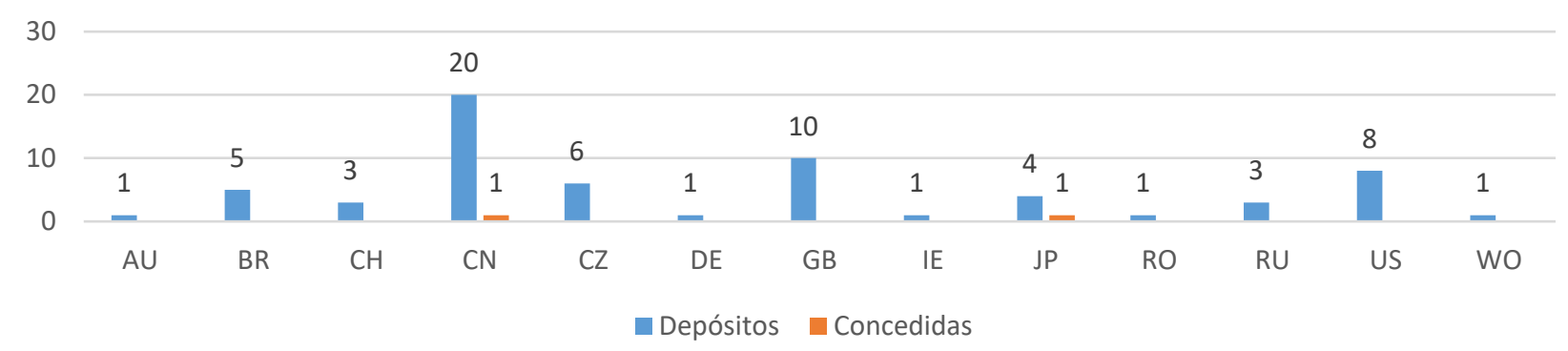

Nota: Au: Austrália; BR: Brasil; CH: Suíça; CN: China; CZ: República Checa; GB: Reino Unido; IE: Irlanda; JP: Japão; RO: Romênia; RU: Rússia; US: Estados Unidos; WO: World Intellectual Property Organization (WIPO).

Fonte: Elaborada pelos autores deste artigo (2018)

Quadro 5 - Patentes concedidas

\begin{tabular}{|c|c|c|c|c|c|c|}
\hline Título & $\begin{array}{l}\text { NúMERo DA } \\
\text { Publicação }\end{array}$ & País & $\begin{array}{c}\text { DATA DE } \\
\text { APLICAÇão }\end{array}$ & $\begin{array}{c}\text { DATA DE } \\
\text { PUBLICAÇÃo }\end{array}$ & Depositante & $\begin{array}{c}\text { DATA DE } \\
\text { CONCESSÃo }\end{array}$ \\
\hline Nutritive food & $\begin{array}{l}\text { JP2015188415 (A); } \\
\text { JP6300600 (B2) }\end{array}$ & JP & 2014 & 2015 & Terumo corp & 2018 \\
\hline $\begin{array}{l}\text { Nutritional tablet for } \\
\text { enhancing immunity }\end{array}$ & $\begin{array}{l}\text { CN105053996 (A); } \\
\text { CN105053996 (B) }\end{array}$ & $\mathrm{CN}$ & 2015 & 2015 & $\begin{array}{c}\text { Fujian xingfu } \\
\text { biotechnology } \\
\text { co ltd }\end{array}$ & 2017 \\
\hline
\end{tabular}

Fonte: Elaborado pelos autores deste artigo (2018)

\subsection{Análise por Depositantes}

As empresas e instituições que mais fizeram depósitos de patentes desde 1925 foram British Petroleum do Reino Unido, C2P SRO da República Checa, a chinesa Mueller Hans Maennedorf e a brasileira Núcleo de Pesquisas Aplicadas (NPA) (Figura 6). Contudo, com o intuito de analisar o mercado atual, os depósitos de maior interesse para esse artigo são os realizados pela C2P $\mathrm{SRO}$ e pelo NPA, pois são patentes mais recentes.

As quatro patentes da C2P SRO foram depositadas em 2010, são classificadas como de invenção e não houve continuação na análise do pedido devido ao não pagamento de taxas. As patentes do NPA possuem data de depósito de 2006 e 2010, são de invenção e estão em processo de análise (Quadro 6). 
Figura 6 - Empresas que mais depositaram patentes desde 1925

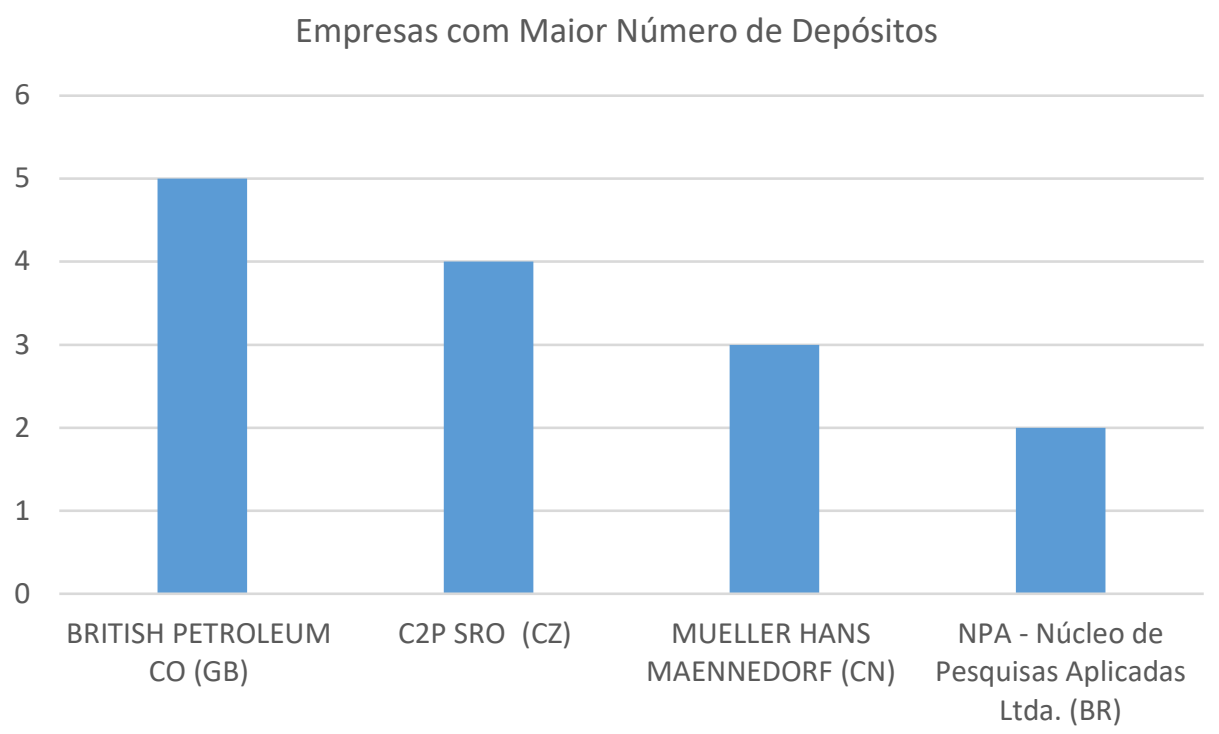

Fonte: Elaborada pelos autores deste artigo (2018)

Quadro 6 - Patentes mais recentes depositadas pela C2P SRO e pelo NPA

\begin{tabular}{|c|c|c|c|c|c|}
\hline Título & $\begin{array}{l}\text { NÚMERO DA } \\
\text { PUBLICAÇÃo }\end{array}$ & País & $\begin{array}{l}\text { DATA DE } \\
\text { APLICAÇÃo }\end{array}$ & $\begin{array}{c}\text { DATA DE } \\
\text { PUBLICAÇÃo }\end{array}$ & Depositante \\
\hline $\begin{array}{l}\text { Food yeast supplement and } \\
\text { process for preparing thereof }\end{array}$ & $\begin{array}{l}\text { CZ20100992 (A3); } \\
\text { CZ306270 (B6) }\end{array}$ & $\mathrm{CZ}$ & 2010 & 2012 & C2P SRO [CZ] \\
\hline $\begin{array}{l}\text { Food yeast supplement and } \\
\text { process for preparing thereof }\end{array}$ & $\begin{array}{l}\text { CZ20100993 (A3); } \\
\text { CZ306271 (B6) }\end{array}$ & $\mathrm{CZ}$ & 2010 & 2012 & C2P SRO [CZ] \\
\hline $\begin{array}{l}\text { Food yeast supplement and } \\
\text { process for preparing thereof }\end{array}$ & $\begin{array}{l}\text { CZ20100994 (A3); } \\
\text { CZ306272 (B6) }\end{array}$ & $\mathrm{CZ}$ & 2010 & 2012 & C2P SRO [CZ] \\
\hline $\begin{array}{l}\text { Process for preparing yeast } \\
\text { protein hydrolyzate }\end{array}$ & $\begin{array}{l}\text { CZ20100991 (A3); } \\
\text { CZ306184 (B6) }\end{array}$ & $\mathrm{CZ}$ & 2010 & 2012 & C2P SRO [CZ] \\
\hline $\begin{array}{l}\text { Composições contendo selênio } \\
\text { para suplementação nutricional }\end{array}$ & PI 0605813-2 & $\mathrm{BR}$ & 2006 & 2008 & $\begin{array}{l}\text { NPA - Núcleo } \\
\text { de Pesquisas } \\
\text { Aplicadas } \\
\text { Ltda. (BR/SP) }\end{array}$ \\
\hline $\begin{array}{l}\text { Complexos minerais contendo parede } \\
\text { celular, processos de preparação, } \\
\text { composições que os contém e } \\
\text { uso desses complexos minerais }\end{array}$ & PI 1002480-8 & $\mathrm{BR}$ & 2010 & 2012 & $\begin{array}{l}\text { NPA - núcleo } \\
\text { de pesquisas } \\
\text { aplicadas ltda. } \\
\text { (BR/SP) }\end{array}$ \\
\hline
\end{tabular}

Fonte: Elaborado pelos autores deste artigo (2018)

\subsection{Análise Qualitativa}

Durante a análise qualitativa das patentes, ficou evidente que a grande maioria dos documentos focava em métodos de preparo de leveduras ou "receitas", nas quais a biomassa deveria ser misturada a outros ingredientes, visando à obtenção de um produto com outras características além de suplementação proteica. 


\section{Considerações Finais}

Pela análise dos bancos de dados no INPI, Espacenet e USPTO fica claro que ainda há pouco investimento na proteção de patentes sobre leveduras nutricionais, pois há apenas 64 depósitos e duas concessões de patentes válidas até a conclusão deste trabalho. Com exceção da China, que possui 20 depósitos na área, todos os outros países depositaram dez ou menos patentes. O Brasil possui mais depósitos do que a maioria dos demais países, mas esse número ainda é reduzido. Esse quadro acaba refletindo no número de patentes concedidas, que é nulo até o momento no País. Portanto essa parcela de mercado ainda não está saturada, é deficiente e pouco aproveitada pelas empresas. Esse déficit é aparente quando se analisa o número de produtos do tipo presentes no Brasil, que ainda é reduzido.

Com esse baixo número de depósitos há uma oportunidade de mercado no Brasil ainda pouco explorada e com grande possibilidade de rendimentos com as leveduras nutricionais, pois o País está em processo de elevação da procura por alimentos saudáveis, suplementos alimentares e no número de pessoas que adotam o vegetarianismo e veganismo como estilo de vida.

Uma hipótese para o reduzido número de patentes na área e pelas poucas empresas que as fazem seria a possível preferência por manter segredo industrial, evitando expor sua tecnologia detalhadamente para o mercado.

Observou-se ainda que a maioria das patentes se refere a "receitas" ou métodos de preparação dos produtos, sendo pouco abordado o uso de biotecnologia para melhoramento genético das cepas de leveduras, tornando-as mais adequadas para o uso como suplemento. Portanto, essa seria uma área para possíveis investimentos e que ainda é pouquíssimo explorada mundialmente.

\section{Referências}

AGÊNCIA NACIONAL DE VIGILÂNCIA SANITÁRIA (ANVISA). Resolução no $\mathbf{1 8}$, de 30 de abril de 1999. Regulamento técnico que estabelece as diretrizes básicas para análise e comprovação de propriedades funcionais e ou de saúde alegadas em rotulagem de alimentos. 1999. Disponível em: $<$ http://portal.anvisa.gov.br/documents/10181/2718376/RES_18_1999_COMP.pdf/dd30fd35-e7ea4f8d-be72-ae2e439191b0>. Acesso em: jul. 2018.

BAUMOL, W. J. Introduction: on the engine of free-market Growth. In: The free market innovation machine. Princeton: Princeton University Press, 2003. Cap. 1.

BEKATOROU, A.; PSARIANOS, C.; KOUTINAS, A. A. Production of food grade yeasts. Food Technol. Biotechnol, Patras, v. 44, n. 3, p. 407-415, 2006.

C2P SRO. HROMADKA, Robert et al. Process for Preparing Yeast Protein Hydrolysate. CZ 20100991 (A3), CZ306184 (B6), 30 dez. 2010.

Food Yeast Supplement and Process for Preparing Thereof. CZ 20100994 (A3), CZ 306272 (B6), 31 dez. 2010.

Food Yeast Supplement and Process for Preparing Thereof. CZ 20100993 (A3), CZ306271 (B6), 31 dez. 2010.

Food Yeast Supplement and Process for Preparing Thereof. CZ 20100992 (A3), CZ 
206270 (B6), 31 dez. 2010.

FUJIAN XINGFU BIOTECHNOLOGY. XUEZHU, Wang; XIANGU, Wang. Nutritional tablet for enhancing immunity. CN 105053996 (A), CN105053996 (B), 17 set. 2015; 10 out. 2017.

GRILICHES, Z. MARKET, Value. In: R \& D, patents and productivity. vol. I, Chicago: University of Chicago Press, 1984. p. 249-252.

INSTITUTO NACIONAL DA PROPRIEDADE INDUSTRIAL (INPI). Diretoria de Patentes. Diretrizes de exame de patentes de modelo de utilidade. 2012. Disponível em: < http://www.inpi.gov.br/ legislacao-arquivo/docs/resolucao_85-13-anexo_diretrizes_mu.pdf >. Acesso em: jul. 2018.

JACH, M. E.; SEREFKO, A. Nutritional yeast biomass: characterization and application. In: HOlBAN, A. M.; GRUMEZESCU, A. M. (Ed.). Diet, Microbiome and Health. Londres: Academic Press, 2018. Cap. 9.

MAYERHOFF, Z. D. V. L. Uma Análise Sobre os Estudos de Prospecção Tecnológica. Cadernos de Prospecção, Salvador, v. 1, n. 1, p. 7-9, 2008.

NÚCLEO DE PESQUISAS APLICADAS Ltda. SERCHELI, Ricardo da Silva; FERNANDES FILHO, Nelson Henriques. Composições Contendo Selênio Para Suplementação Nutricional. BR n. PI 0605813-2 (A2), 22 dez. 2006.

Complexos minerais contendo parede celular, processos de preparação, composições que os contém e uso desses complexos minerais. BR n. PI 10024808 (A2), 2 jul. 2010.

SANTOS, M. DE M. et al. Prospecção de tecnologias de futuro: métodos, técnicas e abordagens.

Parcerias estratégicas, Brasília, DF, n. 19, p. 189-229, dez 2004.

TERUMO CORPORATION (TERUMO). NISHITANI Hiroshi. Nutritive Food. JP 2015188415 (A), JP 6300600 (B2). 28 mar. 2014, 9 mar. 2018.

\title{
Sobre os autores
}

\author{
Natasha Cecchi Evangelista \\ E-mail: natcecchi93@gmail.com \\ Graduada em Biotecnologia, pela Universidade de Brasília (UnB).
}

\section{Grace Ferreira Ghesti}

E-mail: ghesti.grace@gmail.com

Doutora em Química, pela Universidade de Brasília (UnB); mestre em Química, pela (UnB); mestra pelo Programa de Mestrado Profissionalizante em Certified Brewmaster Course Versuchs- und Lehranstalt für Brauerei in Berlin, VLB, Alemanha; bacharel em Química, pela UnB.

Endereço profissional: Instituto de Química. Campus Darcy Ribeiro, Universidade de Brasília - Asa Norte, Brasília, DF. 


\section{Nádia Skorupa Parachin}

E-mail: nadiasp@gmail.com

Doutora em Engenharia Metabólica e em Microbiologia Aplicada, pela Lund University; mestre em Ciências Biológicas (Biologia Molecular), pela Universidade de Brasília (UnB); bacharel e licenciada em Ciências Biológicas, pela UnB.

Endereço profissional: Laboratório Engenharia de Biocatalisadores, Instituto de Ciências Biológicas, Bloco K, $1^{\circ}$ andar. Campus Darcy Ribeiro, Universidade de Brasília - Asa Norte, Brasília, DF. 